\title{
The effect of enforcing some direct tax law
}

\author{
Hassan Ghodrati, Seyyed Ali Lajevardi and Sajjad Kadkhodayee*
}

Department of Management and Accounting, Kashan Branch, Is Kerman Branch, Iran

\begin{tabular}{l}
\hline C H R O N I C L E \\
\hline Article history: \\
Received January 20, 2014 \\
Accepted 5 July 2014 \\
Available online \\
July 92014 \\
\hline Keywords: \\
Tax \\
Article 181 of Direct Tax Law \\
Taxpayer \\
Tax compliance \\
Tax evasion
\end{tabular}

\section{Introduction}

In recent years, the governments of some middle-east countries have set some policy to decrease budget's reliance on oil revenues and to increase of non-oil resources share, especially tax revenues through reinforcement and modification of tax system. Tax revenues are relatively less fluctuating and lead to bigger accountability of government to people. Tax revenues are considered as a low-cost source of finance in any country, they can play different roles in adjusting income and wealth and it can improve social and economic justice. It can also prevent of exacerbating income inequality through redistribution providing an important and efficient tool for implementing government policy against the economic crisis. However, there some challenges on many countries' tax systems such as absence of an efficient mechanism to collect taxes or a unified view on the taxpayers. Reforming the tax system has been recently one of the most important economic issues in Iran and politicians have emphasized on it in all of the programs and reform projects. While important actions were taken in different ways with the purpose of reforming tax system, such as reforming laws and regulations, *Corresponding author.

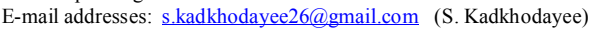


reforming of tax rates and exemptions, vast reforming of processes of assessment or collecting taxes in Tax Offices during the country's developmental programs, there are still many problems in Iran's tax system. There are many factors threatening Iran's economy for various years. Less than 10 percent of taxes are allocated to GDP that is totally different with developed countries. In addition, taxes provided by oil revenues are lower than the state's running costs, budget deficit and government debt to banks and insurance. Although tax rates are so high, tax revenues are still lower than GDP. There are several reasons such as lack of knowledge in tax system, absence of multiplicity of tax rates in various economic parts and underground economy. Some other reasons include wide range of tax exemptions and preferences, personal opinions in the process of tax collection, lack of sufficient mastery of some Tax Officers on the proper enforcement of relevant laws and regulations, expansion of corruption in some tax departments due to insufficient technical monitoring on processes of assessment and collecting taxes. In Iran, paying attention to Article 114 of the Fifth Development Plan regarding increasing tax revenues through budget and GDP will reveal the importance of this issue. In fact, how it can be expected that this article be effective without taking appropriate policies to compensate weaknesses of the tax system in identifying people who corrupt production with activity in the underground economy and evade tax payment, without recognizing new sources of tax, and ultimately without omission of discriminatory tax breaks.

Article 181 of Direct Tax Law is codified to monitor enforcing tax laws and regulations. According to this code and suggestion of the state tax office's employer, all of offices, taxpayers' financial documents and applications, whether related to the year they referred to the Tax Office or the previous years, receive an inspect intrusively. The purpose of this study is to find out the effects of enforcing Article 181 of the Direct Tax Law on the amount of state tax revenues. There are several studies associated with tax system in Iran. Talebnia, (2008) reported that, full tax compliance had been one of the purposes that all of the tax systems could have tried to achieve. In fact, degree of tax compliance was the touchstone of evaluating efficiency of tax system in each country. Brown and Mazur (2003) stated that tax compliance was a theoretical and multifaceted concept investigated in three submissions including compliance in payment, obedience, and reporting.

Organization of Economic Cooperation and Development (O.A.C.D., 2001) divided compliance into two administrative and technical or technological sections. Administrative compliance is associated with the country's administrative rules and technical compliance and it refers to compliance in reporting, in processes, which comply with the law, and in necessary technical rules needed for calculation or payment of the tax. The degree of non-compliance can be measured using tax gap. The tax gap is the amount of collected tax minus the amount, which was possible to collect in full compliance of the taxpayers. In recent decades, tax researches have been mainly based on why some people are paying taxes and others evade (Aghaee, 2001). Slemrod (1985) showed in his research when the ultimate effective rate was higher than tax, tax evasion could increase. However, there was no evidence to justify that people with higher income had more tax evasion than low-income people.

Balestrino (2010) provided a model of tax evasion for heterogeneous contexts. In the first stage of the study, it was hypothesized that the psychological costs of tax evasion could lead to paying progressive or increased tax. In the second stage, shame and guilt in a game followed modeling groups. Then, it was argued that shame and guilt resulting from tax evasion for the low-income people was not so high. Therefore, only when there was a strong democracy, social tax evasion would lead to a widespread conviction. Buehn and Schneider (2012) investigated tax non-compliance and tax evasion as the most important challenges in tax arguments between member countries of the Organization for Economic Cooperation and Development over the period 1999-2010. According to this study, taking into account indirect taxes and self-employment as the stimulant factors of tax evasion, a decreasing trend is observed among all 38 members of countries. Mean of tax evasion for the 38 countries was $3.2 \%$ of GDP in the mentioned period of time. Mexico and Turkey with 7.6 and 8.6 percent had the highest mean of tax evasion, respectively. America with $0.5 \%$ and Luxembourg with $1.3 \%$ had the lowest tax evasion. Khan Jan (2007) investigated the role of official bodies 
(especially four bodies of constitution, government, Direct Tax Law, and tax system) encountering deliberate non-compliance or tax evasion in Mashhad, Iran. His study indicated that all of the subjects had a history of deliberate tax evasion (non-compliance) in their last financial year and did not possess an optimistic view towards official bodies. Mousavi Jahromi (2008) declared although politic, social, and management factors are effective in tax compliance, effective role of the tax system in assessing and dealing with non-compliance con not be ignored or be considered less important. It is obvious that as the equipment and administrative and management ability of the Tax Offices and tax payers' awareness enhances, tax payers' motivation for non-compliance decreases. Seyed Nourani (2010) declared non-compliance equal to the amount of tax gap. He reports, tax gap including tax evasion, deferred taxes, taxes which are declared but not paid, taxpayers' mistakes in declaration and payment of tax, Tax Officers' mistakes in assessment, leads to non-compliance. In addition, maybe tax laws contain some ways for tax evasion or possibility for delay in tax payment.

\section{The proposed study}

The main question is "To what extent enforcing Article 181 of the Direct Tax Law is effective in the research domain?". To answer this question, we need to answer the following four questions,

1. To what extent enforcing Article 181 is effective in increasing taxpayers' trust?

2. To what extent enforcing Article 181 is effective in increasing taxpayers' satisfaction?

3. To what extent enforcing Article 181 is effective in increasing taxpayers' awareness?

4. To what extent enforcing Article 181 is effective in increasing taxpayers' compliance?

Since the purpose of the study was based on concepts, theories, and existed models to improve the situation, method of the study was implicational. Sample of the study was selected randomly and analytical or inductive methods were used. The design of the study was survey in investigating participants' comments and it was Expose Facto based on inferences gained from previous experiences in evaluating effectiveness of enforcing Article 181 of Direct Tax Law. The population of this study consisted of all companies which Article 181 of the Direct Tax Law had been implemented on and their log on tax was classified in Inspection and Supervision Organization of Tax Office. Final tax was detected for all of these companies before and after enforcing the Article181. In this study, $\alpha=5 \%, \mathrm{z}^{2} \alpha / 2=1.96$, and $\mathrm{D}^{2}$ was equal to $\beta$, and according to Cochran's formula the sample size was calculated 96.04 but 100 companies were participated cautiously since the possibility of the second type of mistake is usually $10 \%$ in similar studies. In addition, these companies were selected randomly based on kind of their activities. In addition to the related questionnaires, which were distributed among the owners or CEO as the taxpayers, information about the performance of the sample companies before and after enforcing the Article was collected. The study uses ANOVA test with Kruskal-Valis criterion to analyze the concordance between participants' comments. Participants were categorized in different groups based on demographic variables (gender, age, occupation, education, type of activity) and their comments on each question of the study were investigated regardless of the group they belong to.

- Ratio test was employed to investigate meaningfulness of the ratio of the agreed participants with parametric test.

- A test was used to measure the ratio of tax compliance before and after the enforcing Article 181 of Direct Tax Law. Ratio measuring was based on submitted tax to detected tax.

The mathematical method is represented as $E=f\left(X_{1}, X_{2}, X_{3}, X_{4}\right)$ where $E$ is the extent of effectiveness of enforcing Article 181 of Direct Tax Law as a dependent variable and $X_{1}, X_{2}, X_{3}, X_{4}$ are independent variables associated with the rate of tax compliance, taxpayers' awareness, taxpayers' satisfaction, and taxpayers' trust on State Tax Office and its performance, respectively. Tax compliance is defined as the ratio of submitted tax to the detected tax which is in fact the complement of tax evasion. Effectiveness of two dependent variables is judged based on a positive 
change in their ratio over time, while effectiveness of other independent variables was measured based on a survey. Additionally, the research model can be graphically depicted in Fig. 1 as follows,

\begin{tabular}{|c|c|c|}
\hline Input & Calculation and analysis & Output \\
\hline Survey & $\begin{array}{c}\text { Test of ratio for assessing change in tax compliance over } \\
\text { time } \\
\text { Test of concordance analysis } \\
\text { Ratio test } \\
\text { Other tests }\end{array}$ & $\begin{array}{l}\text { Effectiveness of Article in } \\
\text { population's point of view }\end{array}$ \\
\hline
\end{tabular}

Fig. 1. Conceptual model of the study

At the beginning of the questionnaire, five demographic questions related to the age, gender, marital status, education level, and management experience were asked. Despite researcher's pursuing and recourse to the participants, among 100 questionnaires, one was remained unanswered and the others were answered, completely. According to the completed questionnaires, demographic characteristics of the sample were shown in Fig. 2. Regarding gender, all of the participants were male without exception and no female participant had taken part in the survey. 97 were married, 2 were single, and one was without answer.

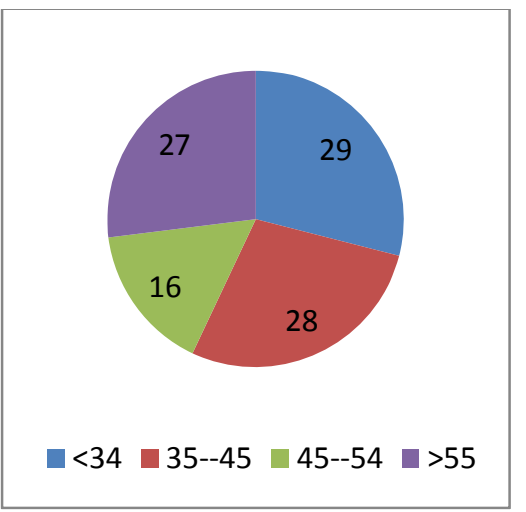

Age

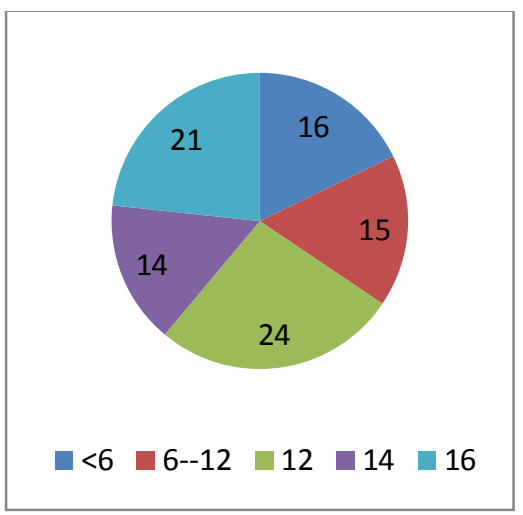

Years of education

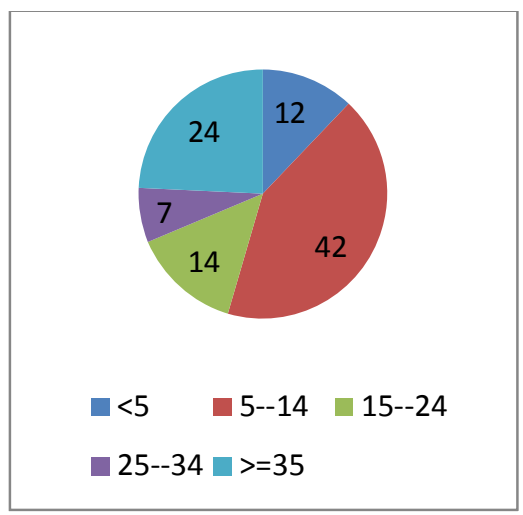

Job experience

Fig. 2. Personal characteristics of the participants

The questionnaire of the study included 20 main questions associated with the extent of taxpayers' satisfaction, trust, and awareness regarding to the effectiveness of Article 181 of the Direct Tax Law. Table shows the results of our survey.

Table 1

The results of the survey regarding the questions of the study

\begin{tabular}{|c|c|c|c|c|c|c|}
\hline item & Summary of the question & Very little & Little & Medium & Much & Very much \\
\hline 1 & Degree of familiarity with enforcing Article 181 & 29 & 25 & 34 & 9 & 2 \\
\hline 2 & Degree of familiarity with tax declaration system & 7 & 26 & 38 & 22 & 5 \\
\hline 3 & Degree of familiarity with tax assessment system & 30 & 30 & 27 & 11 & 1 \\
\hline 4 & Effectiveness of methods for assessment & 8 & 19 & 30 & 33 & 8 \\
\hline 5 & Effectiveness of Article 181 on tax compliance & 4 & 13 & 26 & 33 & 20 \\
\hline 6 & Effectiveness of Article 181 on the taxpayers' satisfaction & 9 & 5 & 29 & 32 & 23 \\
\hline 7 & Effectiveness of Article 181 on interaction with taxpayers & 5 & 11 & 31 & 30 & 18 \\
\hline 8 & Impact of Tax Office's employees on developing trust & 3 & 8 & 24 & 40 & 22 \\
\hline 9 & Adequacy of facilities to meet taxpayers' expectations & 6 & 12 & 44 & 28 & 9 \\
\hline 10 & Effectiveness of employees' familiarity with Article 181 & 4 & 10 & 37 & 33 & 13 \\
\hline 11 & Appropriateness of employees in the Tax Office & 4 & 4 & 36 & 33 & 22 \\
\hline 12 & Nondiscrimination in employees' responses to the & 6 & 14 & 30 & 37 & 12 \\
\hline 13 & Taxpayers' satisfaction with enforcing Article 181 & 5 & 13 & 24 & 25 & 28 \\
\hline 14 & Adequacy of moratorium on tax declaration & 14 & 21 & 29 & 23 & 6 \\
\hline 15 & Satisfaction with response time to submitting declarations & 8 & 15 & 36 & 27 & 8 \\
\hline 16 & Degree of familiarity with the informing unit of the Tax & 21 & 21 & 29 & 20 & 7 \\
\hline 17 & Success of teaching and promotion unit in informing & 31 & 28 & 22 & 13 & 3 \\
\hline 18 & Employees' proficiency in enforcing Article 181 & 3 & 14 & 32 & 27 & 13 \\
\hline 19 & Degree of certainty about method of enforcing Article & 6 & 10 & 31 & 35 & 7 \\
\hline 20 & Effectiveness of enforcing Article 181 on developing & 1 & 13 & 41 & 21 & 19 \\
\hline
\end{tabular}


In this survey, ANOVA test with Kruskal-Wallis was used to investigate the effect of demographic variables on participants' comments regarding the main questions of the study. As all of the participants were male and vast majority were married, these two variables were eliminated and comments were solely analyzed based on education level.

\subsection{The effect of education level on the participants' comments}

Investigating the questions of the study showed all of the participants, regardless of their education level, agreed with each other only upon two questions of the study, i.e. 2 and 11. These were degree of familiarity with declaration and assessment and accountability of Tax Office respectively. Participants did not agree completely upon the other questions of the study. Participants were classified based on their education level into five groups: elementary, guidance, diploma, higher than diploma, and bachelor's degree or higher. Investigating comments based on these five groups showed there was a direct correlation between education level and degree of the effect of considered variable. In other words, people with higher education level reported more effect and selected the choices with higher effect. The analysis of concordance between participants' comments regarding their education level is summarized in Table 2 as follows.

Table 2

The Summary Results of Education Level ANOVA

\begin{tabular}{|c|c|c|c|c|c|}
\hline Description & No. 1 & No. 2 & No. 3 & No. 4 & No. 5 \\
\hline Statistic & 6.049 & 34.749 & 6.347 & 7.359 & 4.969 \\
\hline Degree of freedom & 4 & 4 & 4 & 4 & 4 \\
\hline Sig. Level & 0.195 & 0.000 & 0.137 & 0.120 & 0.291 \\
\hline Description & No. 6 & No. 7 & No. 8 & No. 9 & No. 10 \\
\hline Statistic & 2.030 & 1.768 & 5.506 & 5.871 & 6.507 \\
\hline Degree of freedom & 4 & 4 & 4 & 4 & 4 \\
\hline Sig. Level & 0.730 & 0.778 & 0.239 & 0.239 & 0.136 \\
\hline Description & No. 11 & No. 12 & No. 13 & No. 14 & No. 15 \\
\hline Statistic & 10.560 & 2.712 & 3.343 & 2.479 & 7.101 \\
\hline Degree of freedom & 4 & 4 & 4 & 4 & 4 \\
\hline Sig. Level & 0.032 & 0.608 & 0.502 & 0.645 & 0.131 \\
\hline Description & No. 16 & No. 17 & No. 18 & No. 19 & No. 20 \\
\hline Statistic & 6.293 & 0.857 & 0.656 & 2.026 & 5.041 \\
\hline Degree of freedom & 4 & 4 & 4 & 4 & 4 \\
\hline Sig. Level & 0.178 & 0.762 & 0.952 & 0.721 & 0.283 \\
\hline
\end{tabular}

\subsection{Investigating the effect of other demographic variables on participants' comments}

As two other variables, the participants' age and their management experience, were (discrete) quantitative, Spearman's rank correlation coefficient used for measuring their effect on participants' comments. Investigating questions $2,5,14,15$, and 17 showed that there was no meaningful correlation between the participants' age and their comments. In addition, there were no similar comments on these questions. The topics were as follows: familiarity with declaration and assessment system, effect of enforcing Article 181 of Direct Tax Law on taxpayers' tax compliance, suitability of moratorium for tax declaration, satisfaction with the time period for declaration and handling, and success of teaching and promotion unit in informing taxpayers. Correlation between the participants' age and their comments on the research's questions was meaningful regarding all of the questions, except the above mentioned. This correlation coefficient was negative for questions $1,3,6,7,10,12$, 13,19 , and 20 that is representative of a negative or indirect correlation or effect. That is to say, as the participants' age increases the effect of the considered variables decreases. However, this correlation was positive and there was a direct correlation regarding questions 4, 8, 9, 16, and 18 . However, absolute value of this coefficient is between zero to thirty percent that indicates a weak relationship. Investigating the effect of taxpayers' management experience on their comments on 20 questions of the study, there was a meaningful correlation between these two variables represented in questions 2 and 15, which were degree of familiarity with assessment and handling system, and suitability of the time of submitting tax declaration. No agreement was observed between the 
participants' answers to the questions, except question 2 and 15, regarding to the management experience. In Levels of fewer than $5 \%$ it can be claimed that their comments were dependent on their experience. As the participants' management experience increases, the effect of the considered variable decreases and vice versa. This holds on questions $1,3,4,6,7,8,9,10,11,12,13,14,17$, and 20 that there is an indirect correlation. Regarding other questions including 18 and 19, management experience had a positive effect on their comments and the correlation was direct. However, absolute value of the Spearman's correlation coefficient for each individual question and management experience was 3 or less than $30 \%$. So it can be claimed that the correlation between management experience and method of commenting on the questions was weak. Table 3 shows the correlation coefficient, which is calculated and its level of meaningfulness.

Table 3

The Summary Results of Age and Extortionate ANOVA

\begin{tabular}{lcccccccccc}
\hline Description & No. 1 & No. 2 & No. 3 & No. 4 & No. 5 & No. 6 & No. 7 & No. 8 & No. 9 & No. 10 \\
\hline Age: & & & & & & & & & & \\
Correlation & -0.131 & -0.255 & -0.141 & 0.052 & -0.226 & -0.158 & -0.133 & 0.039 & 0.099 & -0.0111 \\
Sig. Level & 0.255 & 0.005 & 0.147 & 0.621 & 0.031 & 0.129 & 0.21 & 0.714 & 0.343 & 0.292 \\
\hline Extortionate: & & & & & & & & & & \\
Correlation & -0.066 & -0.243 & -0.095 & -0.023 & 0.025 & -0.001 & -0.074 & -0.082 & -0.093 & -0.109 \\
Sig. Level & 0.571 & 0.037 & 0.416 & 0.785 & 0.844 & 0.991 & 0.54 & 0.488 & 0.247 & 0.357 \\
\hline Description & No. 11 & No. 12 & No. 13 & No. 14 & No. 15 & No. 16 & No. 17 & No. 18 & No. 19 & No. 20 \\
\hline Age: & & & & & & & & & & \\
Correlation & 0.075 & -0.084 & -0.199 & -0.222 & -0.209 & 0.131 & -0.307 & 0.031 & -0.1 & -0.0183 \\
Sig. Level & 0.468 & 0.65 & 0.061 & 0.038 & 0.049 & 0.211 & 0.003 & 0.782 & 0.365 & 0.084 \\
\hline Extortionate: & & & & & & & & & & \\
Correlation & -0.142 & -0.126 & -0.19 & -0.125 & -0.282 & 0.013 & -0.058 & -0.028 & 0.084 & -0.214 \\
Sig. Level & 0.222 & 0.28 & 0.113 & 0.301 & 0.017 & 0.909 & 0.622 & 0.836 & 0.501 & 0.073 \\
\hline
\end{tabular}

\subsection{Evaluating effectiveness}

The effectiveness of developing trust, increasing taxpayers' knowledge and awareness, taxpayers' satisfaction, increasing tax compliance is evaluated.

\subsubsection{Developing trust}

Questions 4, 5, 7, 8, 9, 18, 19, and 20 are associated with the effect of enforcing Article 181 of the Direct Tax Law on increasing taxpayers' trust in Tax Office and its performance. Table 4 shows comments of the taxpayers who were agree in the executed survey.

Table 4

Trust Acceptation Ratio

\begin{tabular}{ccccc}
\hline Question No. & Medium & Much & Very Much & Total \\
\hline 4 & 30 & 33 & 8 & 71 \\
5 & 26 & 33 & 18 & 79 \\
7 & 31 & 30 & 22 & 79 \\
8 & 24 & 40 & 9 & 86 \\
9 & 44 & 28 & 13 & 71 \\
18 & 32 & 27 & 19 & 72 \\
19 & 31 & 21 & 116 & 81 \\
20 & 41 & 247 & & 622 \\
\hline Total & 259 & & &
\end{tabular}

According to the results represented in Table 4, degree of agreement with the effect of enforcing Article 181 on increasing trust in Tax Office is measured calculating $\hat{p}$ :

$\hat{p}=\frac{622}{8 \times 99}=0.7854$ or $78.54 \%$ 
As " $n$ " or the size of random sample tends to infinity $\mathrm{H}_{1}$ is defined in based on $\mathrm{P}>.07$ or $\mathrm{P}<.07$

$\mathrm{T}=\frac{0.7854-0.7}{\sqrt{\frac{0.7(0.3)}{99}}}=1.8542$

Based on statistical decisions, if the test statistic were between minus infinity to $1.645 \mathrm{H}_{0}$ hypothesis would be accepted, otherwise it should be rejected. Therefore, more than $70 \%$ of the taxpayers, with $95 \%$ possibility, agreed with the effect of enforcing Article 181 of Direct Tax Law on developing trust.

\subsubsection{Increasing knowledge and awareness}

Questions 1, 2, 3, 16, and 17 were related to the effect of enforcing Article 181 of Direct Tax Law on the level of employers' knowledge and awareness of tax laws, objectives, functions, and status of the Tax Office. Table 5 summarizes comments of the taxpayers who agreed in the survey.

Table 5

Knowledge Acceptation Ratio

\begin{tabular}{|c|c|c|c|c|}
\hline Question No. & Medium & Much & Very Much & Total \\
\hline 1 & 35 & 9 & 2 & 46 \\
\hline 2 & 38 & 22 & 5 & 65 \\
\hline 3 & 27 & 11 & 1 & .39 \\
\hline 16 & 29 & 20 & 7 & 56 \\
\hline 17 & 28 & 22 & 13 & 63 \\
\hline Total & 157 & 84 & 28 & 269 \\
\hline
\end{tabular}

According to the results of taxpayers' comments who agreed with effect of enforcing Article 181 of Direct Tax Law on increasing level of familiarity with and awareness towards tax laws, objectives, functions of the Tax Office, $\hat{p}$ is calculated as an estimate of proportion or percentage of agreed participants:

$\hat{p}=\frac{269}{5 \times 99}=0.5434$ or $54.34 \%$

To generalize the results to all employers in the study, hypothesis of $\mathrm{H}_{1}$ based on $\mathrm{P}>.5$ is examined against $\mathrm{P}<.5$. The numerical value of the test criterion is as follows:

$\mathrm{T}=\frac{0.5434-0.5}{\sqrt{\frac{0.5(0.5)}{99}}}=0.8636$

As the acceptance level for $\mathrm{H}_{0}$ in statistics is between $-\infty$ to 1.96 and the numerical value of the test criterion stands in this distance, $\mathrm{H}_{0}$ hypothesis is accepted and $\mathrm{H}_{1}$ is rejected. That is to say, participants who claimed enforcing Article 181 of Direct Tax Law had a positive effect on the employers' awareness of and familiarity with Tax Office's laws, objectives, and functions were lower than or equal to 0.5 .

\subsubsection{Satisfaction}

Questions 6,10,11,12,13,14, and 15 were related to the taxpayers' satisfaction with Tax Office's performance. Table 6 shows the agreed comments in the survey. Regarding to the summarized results in Table 6 related to the comments on the effect of enforcing Article 181 on increasing employers' satisfaction with Tax Office, $\hat{p}$ is calculated as shown below:

$\hat{p}=\frac{544}{7 \times 99}=0.7850$ or $78.50 \%$ 
Table 6

Satisfaction Acceptation Ratio

\begin{tabular}{ccccc}
\hline Question No. & Medium & Much & Very Much & Total \\
\hline 6 & 29 & 32 & 23 & 84 \\
10 & 37 & 33 & 22 & 83 \\
11 & 36 & 34 & 12 & 92 \\
12 & 30 & 37 & 28 & 79 \\
13 & 24 & 25 & 6 & 77 \\
14 & 29 & 23 & 8 & 58 \\
15 & 36 & 27 & 112 & 71 \\
\hline Total & 221 & 211 & 544 \\
\hline
\end{tabular}

To generalize the results obtained from the random sample, hypothesis $\mathrm{H}_{1}, \mathrm{P}>0.7$ is examined against $\mathrm{H}_{0}, \mathrm{P}<0.7$. The numerical value of the test criterion is as follows:

$\mathrm{T}=\frac{0.7850-0.7}{\sqrt{\frac{0.7(0.3)}{99}}}=1.8456$

Regarding to the decision making rule in which the numerical distance between $-\infty$ to 1.645 is defined as the acceptance level for $\mathrm{H}_{0}$ and complement of this distance as the critical region or rejection for $\mathrm{H}_{0}$ and since the numerical value of the test criterion, $1 / 8456$, is situated in the rejection region, hypothesis $\mathrm{H}_{0}$ is rejected and $\mathrm{H}_{1}$ is accepted. In other words, $70 \%$ of the participants agreed upon, with the possibility of $95 \%$, the effect of enforcing Article 181 on increasing employers' satisfaction with Tax Office.

\subsubsection{Tax compliance}

In order to assess the effectiveness of enforcing Article 181 to increase taxpayers' tax compliance, the amount of declared and assessed tax and also rates of tax compliance before and after enforcing Article are declared in Million Rials. Statistical indicators to evaluate tax compliance before and after enforcing Article are shown in Table 7.

\section{Table 7}

The Summary of Compliance Criteria Description

\begin{tabular}{lcccc}
\hline Variable & Mean & St. Deviation & Minimum & Maximum \\
\hline Diagnose Tax before Rule Fulfillment & 644169 & 3257966 & 12215 & 32165145 \\
Declaration Tax before Rule Fulfillment & 42807723 & 221233461 & 757330 & 2187229860 \\
Compliance Ratio before Rule Fulfillment & 65 & 3 & 60 & 69 \\
Diagnose Tax after Rule Fulfillment & 772997 & 3909559 & 14658 & 38598174 \\
Declaration Tax after Rule Fulfillment & 58142285 & 289596367 & 1064534 & 2856264876 \\
Compliance Ratio after Rule Fulfillment & 76 & 3 & 70 & 80 \\
\hline
\end{tabular}

To generalize the results of the study regarding the effect of enforcing Article 181 on increasing tax compliance $\mathrm{H}_{0}$ and $\mathrm{H}_{1}$ are defined as $\left\{\begin{array}{l}H_{0}: P_{2} \leq P_{1} \Rightarrow P_{2}-P_{1} \leq 0 \\ H_{0}: P_{2}>P_{1} \Rightarrow P_{1}-P_{2}>0\end{array}\right.$.

In these hypotheses, $\mathrm{P}_{1}$ and $\mathrm{P}_{2}$ are the ratio of compliance or absence of tax evasion before and after enforcing Article 181 of Direct Tax Law. The employed variables in this test are as follows: $\alpha$, level of the test or the probability of the first kind of error which is considered $5 \%$ in social sciences, $\mathrm{n}_{1}$ and $\mathrm{n}_{2}$, sufficiency of the random sample size which is according to the sample size formula. Test criterion is defined as:

$$
T=\frac{\left(\hat{P}_{2}-\hat{P}_{1}\right)-\left(P_{2}-P_{1}\right)}{\sqrt{\frac{\hat{P}_{1}\left(1-\hat{P}_{1}\right)}{n_{1}}+\frac{\hat{P}_{2}\left(1-\hat{P}_{2}\right)}{n_{2}}}} \quad N(0,1)
$$


$Y_{2}$ : is represented as declaration tax in the studied sample in Isfahan companies after enforcing Article 181.

$X_{2}:$ is the assessed tax in the studied sample in Isfahan companies after enforcing Article 181.

$\hat{P}_{2}$ is obtained by the dividing $X_{2}$ to $Y_{2}$. Similarly, these equations can be employed to measure ratio of tax compliance or absence of tax evasion before enforcing Article 181 of Direct Tax Law. In this case:

$Y_{1}$ : is the declaration tax in the studied sample in Isfahan companies before enforcing Article 181.

$X_{1}$ : is the recognized tax in the studied sample in Isfahan companies before enforcing Article 181.

$\hat{P}_{1}$ is obtained by the dividing $X_{2}$ to $Y_{2}$. According to the calculations, $\hat{P}_{1}$ equals to 0.65 and $\hat{P}_{2}$ equals to 0.76 and the value of the test is 6.542 . Based on the numerical value of the test criterion and Quantrill of standard normal distribution in decision rules which equals to 5\%, the right domain of the distinction or $-\infty$ to 1.645 is the acceptance distinction of $\mathrm{H}_{0}$ and its complement in the right and left sides is called the critical or rejection domain of $\mathrm{H}_{0}$, i.e. the numerical value of the test criterion is situated in the criterion domain; as a result $\mathrm{H}_{0}$ is rejected and $\mathrm{H}_{1}$ is accepted. In other words, enforcing Article 181 of the Direct Tax Law had a meaningful effect on increasing tax compliance and decreasing tax evasion in Isfahan.

Wilcoxon test results were approximately similar to that of the compliance tests summarized in table 8. Increased tax compliance or decreased tax evasion is represented with a positive point and decreased tax compliance or increased tax evasion regarding to the period before enforcing Article 181 is shown with a negative point.

Table 8

The Summary of Signs Test

\begin{tabular}{cccc}
\hline Description & Number & Ranking Mean & Rank Total \\
\hline Negative Signs & 18 & 29.89 & 51.11 \\
Positive Signs & 75 & - & 3833 \\
Similar Signs & 7 & - & - \\
\hline Total & 100 & - & $Z=6.12341$
\end{tabular}

According to the results of Table 8, Positive signs mean that $\mathrm{P}_{1}$ is bigger than $\mathrm{P}_{2}$. In this table, negative sign means that, $\mathrm{P}_{1}$ is smaller than $\mathrm{P}_{2}$. In addition, it can be concluded results of Wilcoxon rank test is almost similar to that of parametric test of investigating the effect of enforcing Article 181 of the Direct Tax Law on increasing tax compliance in Isfahan.

The positive effect of enforcing Article 181 of the Direct Tax Law on tax compliance can be represented in another way. In this respect, we compared the transmittance and the distribution of tax compliance ratios before and after the enforcing the Code. Fig. 2 objectively shows the distribution of tax compliance ratios before and after the enforcing Article 181.

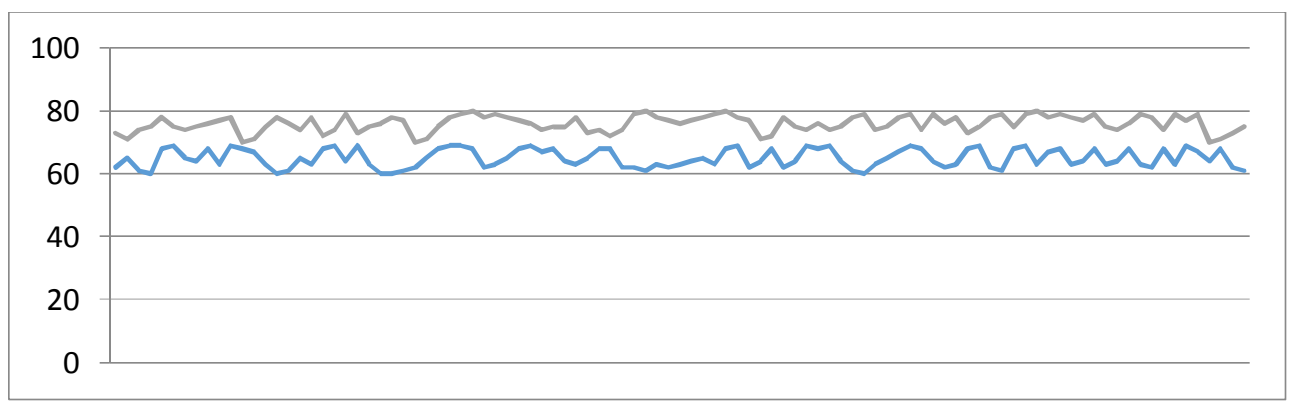

Fig. 2. The Comparison of before and after Compliance Tax Ratio 
As it can be seen in Fig. 2, the ratio of tax compliance, in all of the cases, is increased after enforcing Article 181 of the Direct Tax Law in comparison with the period before that. One can conclude that in most of the cases, tax evasion is decreased after enforcing Article 181 of the Direct Tax Law. Consequently, decreasing tax evasion increases state tax revenues.

\section{Conclusion}

This study is conducted to evaluate the effect of enforcing Article 181 of the Direct Tax Law on degree of satisfaction, awareness, trust, and tax compliance or tax evasion in Isfahan. The gained ratio related to developing trust was 0.7854 . As a result, hypothesis $\mathrm{H}_{1}$, with $95 \%$ confidence level, was accepted stating that more than $70 \%$ of the population agreed upon the positive effect of the enforcing Article 181 of the Direct Tax Law on increasing taxpayers' trust in Isfahan Tax Office. The ratio of the taxpayers' awareness of and familiarity with tax laws and Tax Office and its functions was 0.5434 and the hypothesis stating positive effect of enforcing Article 181 on increasing taxpayers' familiarity is rejected with $95 \%$ confidence level, as the ratio was more than 0.5 . Finally, $\hat{P}$ was equal to 0.7850 in calculations related to the estimation of the ratio of the taxpayers who agreed upon the effect of enforcing Article 181 on increasing taxpayers' satisfaction with the Tax Office. As P was more than 0.7 , thus it is accepted with $95 \%$ confidence level. In other words, more than $70 \%$ of the taxpayers in Isfahan as the population of the study agreed upon the positive effect of enforcing Article 181 on increasing taxpayers' satisfaction with the Tax Office- with the probability of $95 \%$.

Based on performance evaluation, the percent of the average tax compliance in the sample represented as $\mathrm{P}_{1}$ and $\mathrm{P}_{2}$, which were calculated 0.699991266 and 0.891922476 for the period before and after the enforcing Article 181 of the Direct Tax Law, respectively. In the ratio variance test employing parametric method, the hypothesis which stated higher ratio of tax compliance in the period after enforcing the Article than the similar period before the enforcing the Article accepted. The results also confirmed ratio of tax compliance is increased after enforcing Article. In addition, the comparison between the figures of the ratios or percentages of tax compliance before and after the enforcing demonstrates the effect of enforcing the Article on decreasing tax evasion or increasing tax compliance.

\section{References}

Aghaee, A. (2001). Increasing tax quantities in case of serving. Economic bulletin, $1^{\text {st }}$ year.

Brown, RE \& Mazur, M.J (2003). IRS's Comprehensive Approach to Compliance. National Tax Association Spring Symposium, Washington D.C

Balestrino, A. (2010). Tax avoidance and the endogenous formation of social norms. The Journal of Socio-Economics, 39(5), 601-609.

Khan Jan, A. (2007). The role of official organizations in tax evasion (a case study in Mashhad). Tax and Development, 1(1).

Mousavi jahromi, Y. \& Tahmasbi Beldaji, F. (2008). Ways for tax evasion in the system of tax on additional value and methods for preventing. Research article, Tehran, Tax Office.

Organization for Economic Cooperation and Development (EOCD) (2001). Compliance Measurements Practice, Centre for Tax Policy and Administration, Tax Guidance SERies, Available.

Buehn, A., \& Schneider, F. (2012). Size and Development of Tax Evasion in 38 OECD countries: What do we (not) know? (No. 4004). CESifo Working Paper: Public Finance.

Slemrod, J. (1985). An empirical test for tax evasion. The Review of Economics and Statistics, 67(2), 232-238. Seyed nourani, M. (2010). Tax evasion and economic growth in Iran. Tehran, Islamic Legislative Assembly, center of reasearches.

Talebnia, Gh. \& Sheikh Hasani, A. (2008). The comparative investigation of Direct Tax Law with the previous Law in occupation, tenement, and employee's salary. Auditor, 10(36). 